${ }^{3}$ Department of Children's Diabetology, Medical University of Silesia, Katowice

\title{
Evaluation of the quality of life and satisfaction with the therapy in patients with type 1 diabetes - is Medtronic MiniMed 640G system able to improve it? Preliminary insights
}

\section{ABSTRACT}

Introduction. The quality of life (QoL) became a very important parameter in the XXI century which often decides about the type of treatment. The spectrum of treatment possibilities is constantly expanding due to the rapid technological development. Currently most up-to-date MiniMed 640G system which is able to predict hypoglycemia episode, flexibly and transiently stop insulin delivery before approaching programmed low glucose limit and automatically resume it (SmartGuard technology) can become a way to improve the QoL of diabetic patients.

Material and methods. The questionnaire survey was conducted among 10 girls and 14 boys at the age of 2-15 (median 8) years with well-controlled DM1 $\left(\mathrm{HbA}_{1 \mathrm{c}}\right.$ varied from 5.8 to $8.8 \%$, mean $\left.6.7 \%\right)$. The mean time from diagnosis was 3.7 years. The main inclusion criteria was the therapy with $640 \mathrm{G}$ system. Patients were previously treated with insulin pumps with or without hypoblocade (Paradigm ${ }^{\circledR} 722 /$ MiniMed $^{\circledR}$ Veo).

Address for correspondence: Aleksandra Tabor

STN przy Klinice Diabetologii Dziecięcej

Wydział Lekarski w Katowicach

Śląski Uniwersytet Medyczny

ul. Medyków 18, 40-752 Katowice

Phone: 517432425

e-mail: aleksandra.tabor1992@gmail.com

Clinical Diabetology 2017, 6, 1, 1-7

DOI: $10.5603 /$ DK.2017.0002

Received: 27.12 .2016

Accepted: 14.03 .2017
3-11 months after introducing 640G system to therapy during the follow-up visit two surveys were conducted simultaneously: PedsQL ${ }^{T M}$ 3.0 Diabetes which measured the QoL in diabetic patients (Survey I) and the authorial questionnaire (Survey II) which measured the satisfaction of 640G therapy (consisted of 11 questions, 2 closed and 9 semi-closed-ended). Results. Considering participants' answers in Survey I, the mean scores of QoL regarding communication (79\%), concerns $(60 \%)$, treatment $(76 \%)$ and diabetes $(69 \%)$ which according to our scale (0-19\% no impact, $20-39 \%$ low impact, $40-59 \%$ moderate impact, $60-79 \%$ high impact, $80-100 \%$ very high impact) proved that QoL was perceived high. The results of Survey II showed gladness and assurance of the patients with 640G therapy. Relying on their self-observation, over a half of participants (17 people) certified a serious reduction of both hypo/hyperglycemia episodes. 8 patients/caregivers highlighted a great coherence between blood glucose measured by sensor and glucose meter which enabled them to decrease the frequency of pricking fingers. 11 patients considered management of DM1 to be easier, they also noticed better cooperation with 640G system. Conclusion. Patients with DM1 using 640G system are satisfied with the effects of the therapy, they feel safer and their QoL measured by PedsQL is relatively high. (Clin Diabetol 2017; 6, 1: 1-7)

Key words: hypoglycemia, quality of life, sensor-augmented pump therapy, SmartGuard technology 


\section{Introduction}

The quality of life became a very important parameter in the XXI century which often decides about the type of treatment, either its success or failure. The spectrum of treatment possibilities is constantly expanding due to the rapid technological development in the field of diabetology. The model of insulin therapy and the use of appropriate tools are also important issues. Rapidand long-acting insulin analogues, which molecules were modified in order to more closely mimic the physiological insulin excreting and acting, are being used in the modern treatment of diabetes type 1 . They help to reduce the number of both hypoglycemia episodes and postprandial hyperglycemia and the same lower glycaemia fluctuation. The enormous leap forward in measuring blood glucose level also has to be mentioned. Widely available glucometers are frequently being replaced by the continuous glucose monitoring systems (CGM) which can either be integrated with insulin pump (sensor augmented insulin pumps with or without Low Glucose Suspend function) or can be used separately. Researches reveals that CGM reduces time spent outside glucose targets compared with Self-Monitoring of Blood Glucose (SMBG), decreases variability of blood glucose level, improves $\mathrm{HbA}_{1 \mathrm{c}}$ and reduces a number of hypoglycemia episodes [1, 2]. MiniMed Veo ${ }^{\circledR}$ insulin pump is provided with the CGM system and automatic low glucose suspend (LGS) with the possibility of fixed and 2-hours lasting stoppage of insulin delivery when the low blood glucose level measured by sensor is either approaching or already crossed (hypoblocade) [3]. As a comparison, currently most up-to-date MiniMed ${ }^{\circledR}$ 640G system not only has the hypoblocade option but also the SmartGuard ${ }^{\mathrm{TM}}$ technology.

In 2015 Medtronic Inc. group announced introduction of MiniMed ${ }^{\circledR} 640$ G system, which was expected to be another step forward in creating the "artificial pancreas". New insulin pump is able to predict hypoglycemia episode, flexibly and transiently stop insulin delivery before approaching programmed low glucose limit for from half an hour up to two hours if patient did not respond to alerts and automatically resume it
[4] due to the SmartGuard ${ }^{\text {TM }}$ technology. It has already turned out to have a good impact on the treatment process in some studies - De Bock et al. 2014; presented as a conference abstract [5], Choudhary et al. 2015, a case series study presented at American Diabetes Associations conference [6].

These innovative management features of MiniMed $^{\circledR}$ system encouraged our team to conduct and present preliminary data of a prospective, observational, not randomized clinical study evaluating the satisfaction with $640 \mathrm{G}$ therapy.

Aim

The aim is to evaluate the quality of life and satisfaction with the therapy in patients suffering from diabetes type 1 after introducing the Medtronic MiniMed 640G system to the therapy.

\section{Materials and methods}

Research group consisted of patients with diabetes type 1 being treated with MiniMed 640G system for at least 3 months children and their caregivers (those who are leading child's treatment) in patients before the age of 12 years. Participants were recruited from the Department of Children's Diabetology at Medical University of Silesia, which is experienced in the therapy with personal insulin pumps and was the first one in Poland which introduced $640 \mathrm{G}$ system to the common clinical practice. Patients were continuingly using CGM system integrated with MiniMed 640G pump. We collected and analyzed clinical data which are presented in the Table 1. 24 patients (8 caregivers in younger children), aged between 2 and 15 (median 8) years with well-controlled DM1 were examined. Patients were previously being treated with insulin pumps with or without hypoblocade (Paradigm ${ }^{\circledR} 722 /$ MiniMed $^{\circledR}$ Veo).

The psychologist was conducting questionnaires among participants. Obtaining consent for the study was carried out in the following way: for patients before the age of 16 years parent's/caregiver's informed consent, for patients over the age of 16 years parent's and child's consent.

Table 1. Characteristics of the research group

\begin{tabular}{ll}
\hline Gender (M:F) & $14: 10$ \\
Age (years) - median (minimum-maximum) & $8(2-15)$ \\
Mean duration of the DM1 (years) & 3.7 \\
Duration of the MiniMed 640G therapy (months) & $3-11$ \\
$\mathrm{HbA}_{1 \mathrm{c}}$ after introduction of 640G system (\%) - mean (minimum-maximum) & $6.7(5.8-8.8)$ \\
$\mathrm{HbA}_{1 \mathrm{C}}$ before introduction of $640 \mathrm{G}$ system (\%) - mean (minimum-maximum) & $7.0(5.7-8.8)$ \\
\hline
\end{tabular}

DM1 - diabetes mellitus type 1 
We conducted 2 surveys: standardized PedsQL 3.0 Diabetes questionnaire evaluating the quality of life in pediatric patients suffering from diabetes which had been elicited from Mapi Research Trust [7] and authorial questionnaire prepared by psychologist that consisted of 11 questions, 2 closed and 9 semi-closed-ended and was evaluating the current satisfaction with the treatment with Medtronic 640G system and influence of pump changing everyday life (available in 2 versions: for caregiver in patients before the age of 12 years and for patients over the age of 12 years). Surveys consisted of questions related to common everyday life aspects: PedsQL- diabetic problems, treatment, concerns and difficulties in communication and authorial questionnaire- particular limitations that have occurred/have been eliminated, impact on school functioning, exercises, parents' attitude to the disease, frequency of measuring blood glucose level and hypo/hyperglycemia episodes and general satisfaction with the treatment. Full versions of both questionnaires are attached below (Appendix 1, 2).

The manner in which we conducted the surveys depended both on the questionnaire type and patients' age. For patients before the age of 18 years we used PedsQL 3.0 survey evaluating the quality of life. The questionnaire assessing satisfaction with the treatment for patients before the age of 12 years was to be filled by caregiver whereas for patients over this age it was to be filled by patients themselves.

Lack of informed consent and discontinuation of 640G therapy were chosen as exclusion criteria.

\section{Results}

10 girls and 14 boys at the age of 2-15 (median 8) years suffering from DM1 and being treated with MiniMed 640G system for at least 3 months were examined using 2 surveys.

The mean scores of Survey I evaluating the quality of life (PedsQL 3.0) regarding communication: 237/300 (79\%), concerns: 180/300 (60\%), treatment: 836/1100 (76\%) and problems with diabetes: 759/1100 (69\%) which according to our scale (0-19\% very low, 20-39\% low, 40-59\% moderate, 60-79\% high, 80-100\% very high) enable us to state that patients perceived their quality of life high in all categories. The results of Survey II showed gladness and assurance of the patients with 640G system therapy. Over a half of participants - 17 (71\%) certified a serious reduction of both hypo- and hyperglycemia episodes. 8 patients/ /caregivers (33\%) highlighted a great coherence between blood glucose (BG) measured by sensor and glucose meter (GM) which enabled them to reduce the frequency of pricking fingers with GM to measure
BG and improve quality of life. The number of blood glucose measurements decreased by a mean of $50 \%$, with the maximum reduction from 12 to 3.11 caregivers (46\%) noticed greater involvement of children in controlling the disease and also better cooperation with 640G system itself.

Although the study focuses mainly on the quality of life, we also observed improvement of metabolic control: mean $\mathrm{HbA}_{1 \mathrm{c}}$ reduced from $7.0 \%$ (measured before introduction of $640 \mathrm{G}$ into the therapy) to $6.7 \%$ after initiation of the new insulin delivery device.

\section{Discussion}

Most of the published studies on continuous subcutaneous insulin infusion focus on clinical parameters such as $\mathrm{HbA}_{1 c^{\prime}}$ number of both hypoglycemia and hyperglycemia episodes. Nevertheless, diabetes impact on the quality of life cannot be omitted, as it is mostly noticeable from patients' perspective. In our study we decided to assess this extraordinarily important parameter in patients suffering from diabetes type 1 after introducing to the therapy MiniMed 640G system with the SmartGuard ${ }^{\mathrm{Tm}}$ technology. This innovative pump technology is based on different philosophy of insulin treatment with new challenges in education and diabetes self-control. Small number of published studies is caused by the fact of launching 640G system in 2015.

Majority of examined people noticed reduction of hypoglycemia episodes. According to the literature, hypoglycemia is one of the most common acute complications in diabetes treated with insulin and the risk of hypoglycemia can become a psychological obstacle to receiving optimal glycemic control [8]. Severe hypoglycemia is still a huge problem in the group of pediatric patients: rates ranging from 5 to $12 \%$ [9]. It is not only related to unpleasant symptoms but can also frighten pediatric patient and caregivers as well. There are several studies that confirm the reduction of hypoglycemia fear among patients using continuous subcutaneous insulin infusion rather than receiving insulin injections $[10,11]$. According to the results of our survey, MiniMed 640G system helps to reduce the number of hypoglycemia episodes using SmartGuard ${ }^{\mathrm{TM}}$ technology. Because of its ability to predict hypoglycemia and prevent it, pump leads to lower risk of low blood glucose level. Trusting the new technology, it helps patients feel less stressed and more confident about the treatment. Especially parents noticed reduction of hypoglycemia fear, they feel more comfortable about the risk of their child's nocturnal hypoglycemia episodes and their functioning in school or kindergarten.

11 caregivers noticed greater involvement of their children in the treatment process. It seems to be con- 


\section{Appendix 1. PedsQL 3.0 Diabetes questionnaire}

In the past ONE month, how much of a problem has this been for you...

\begin{tabular}{|l|c|c|c|c|c|}
\hline About my diabetes (problems with...) & Never & Almost never & Sometimes & Often & Almost always \\
\hline 1. I feel hungry & 0 & 1 & 2 & 3 & 4 \\
\hline 2. I feel thirsty & 0 & 1 & 2 & 3 & 4 \\
\hline 3. I have to go to the bathroom too often & 0 & 1 & 2 & 3 & 4 \\
\hline 4. I have stomachaches & 0 & 1 & 2 & 3 & 4 \\
\hline 5. I have headaches & 0 & 1 & 2 & 3 & 4 \\
\hline 6. I feel like I need to throw up & 0 & 1 & 2 & 3 & 4 \\
\hline 7. I go "low" & 0 & 1 & 2 & 3 & 4 \\
\hline 8. I go "high" & 0 & 1 & 2 & 3 & 4 \\
\hline 9. I feel tired & 0 & 1 & 2 & 3 & 4 \\
\hline 10. I get shaky & 0 & 1 & 2 & 3 & 4 \\
\hline 11. I get sweaty & 0 & 1 & 2 & 3 & 4 \\
\hline 12. I feel dizzy & 0 & 1 & 2 & 3 & 4 \\
\hline 13. I feel weak & 0 & 1 & 2 & 3 & 4 \\
\hline 14. I have trouble sleeping & 0 & 1 & 2 & 3 & 4 \\
\hline 15. I get cranky or grumpy & 0 & 1 & 2 & 3 & 4 \\
\hline
\end{tabular}

In the past ONE month, how much of a problem has this been for you...

\begin{tabular}{|l|c|c|c|c|c|}
\hline Treatment I (problems with...) & Never & Almost never & Sometimes & Often & Almost always \\
\hline 1. It hurts to get my finger pricked & 0 & 1 & 2 & 3 & 4 \\
\hline 2. It hurts to get insulin shots & 0 & 1 & 2 & 3 & 4 \\
\hline 3. I am embarrassed by my diabetes treatment & 0 & 1 & 2 & 3 & 4 \\
\hline $\begin{array}{l}\text { 4. My spouse, significant other, and/or other family } \\
\text { members and I argue about my diabetes care }\end{array}$ & 0 & 1 & 2 & 3 & 4 \\
\hline $\begin{array}{l}\text { 5. It is hard for me to do everything I need to do to care } \\
\text { for my diabetes }\end{array}$ & 0 & 1 & 2 & 3 & 4 \\
\hline
\end{tabular}

Please answer how hard these things were to do in the past ONE month

\begin{tabular}{|l|c|c|c|c|c|}
\hline Treatment II (problems with...) & Never & Almost never & Sometimes & Often & Almost always \\
\hline 1. It is hard for me to take blood glucose tests & 0 & 1 & 2 & 3 & 4 \\
\hline 2. It is hard for me to take insulin shots & 0 & 1 & 2 & 3 & 4 \\
\hline 3. It is hard for me to exercise & 0 & 1 & 2 & 3 & 4 \\
\hline 4. It is hard for me to keep track of carbohydrates & 0 & 1 & 2 & 3 & 4 \\
\hline 5. It is hard for me to carry a fast-acting carbohydrate & 0 & 1 & 2 & 3 & 4 \\
\hline 6. It is hard for me to snack when I go "low" & 0 & 1 & 2 & 3 & 4 \\
\hline
\end{tabular}

In the past ONE month, how much of a problem has this been for you...

\begin{tabular}{|l|c|c|c|c|c|}
\hline Worry (problems with...) & Never & Almost never & Sometimes & Often & Almost always \\
\hline 1. I worry about going "low" & 0 & 1 & 2 & 3 & 4 \\
\hline 2. I worry about going "high" & 0 & 1 & 2 & 3 & 4 \\
\hline 3. I worry about long-term complications from diabetes & 0 & 1 & 2 & 3 & 4 \\
\hline
\end{tabular}

In the past ONE month, how much of a problem has this been for you...

\begin{tabular}{|l|c|c|c|c|c|}
\hline Communication (problems with...) & Never & Almost never & Sometimes & Often & Almost always \\
\hline 1. It is hard for me to tell the doctors and nurses how I feel & 0 & 1 & 2 & 3 & 4 \\
\hline 2. It is hard for me to ask the doctors and nurses questions & 0 & 1 & 2 & 3 & 4 \\
\hline 3. It is hard for me to explain my illness to other people & 0 & 1 & 2 & 3 & 4 \\
\hline 4. I am embarrassed about having diabetes & 0 & 1 & 2 & 3 & 4 \\
\hline
\end{tabular}




\section{Appendix 2. Authorial questionnaire}

1. How long have you been using insulin pump $640 \mathrm{G}$ for?

2. How can you assess your current comfort level?

Limitations that have occurred:

Limitations that have been eliminated:

3. Does the change in the treatment have impact on your functioning in the school/among contemporaries?

NO

DIFFICULT TO SAY

YES - in which way?

4. Has your attitude to the disease changed since the start of the treatment with $640 \mathrm{G}$ insulin pump?

NO

DIFFICULT TO SAY

YES - in which way?

5. Has your adherence to the rules of healthy diet changed?
NO
DIFFICULT TO SAY

YES - in which way?

6. Are you more physically active? Does the $640 \mathrm{G}$ insulin pump help to plan activities better?

NO

DIFFICULT TO SAY

YES - in which way?

7. Does the treatment with $640 \mathrm{G}$ insulin pump have impact on:

Number/frequency of hyperglycemia episodes - in which way?

Number/frequency of hypoglycemia episodes - in which way? .

Number/frequency of blood glucose level measurements - in which way?

8. How do you assess the possibility of monitoring the treatment in comparison with the prior form of therapy?

MUCH BETTER

THE SAME

WORSE

9. How do you assess the possibility of your self-control with $640 \mathrm{G}$ insulin pump? (for example: easier/more difficult bolus administration)

10. What is the level of your current acceptance of the disease?
FULL ACCEPTANCE
PARTIAL ACCEPTANCE
LACK OF ACCEPTANCE

11. Are you satisfied with the current form of therapy? Does it reach your expectations?

YES - why?

NO - why? 
nected with the fact that children grow up surrounded by variety of technological inventions to play and learn whereas the modern and colorful display of the pump attracts their attention. They are interested in pump's way of working and willingly to try to use it on their own. Referring to caregivers' observations, 640G system became even a gadget to be proud of for few of patients because of its up-to-date look. Because of the attractive manner of presenting glycaemia, its trends, active insulin and other parameters, MiniMed pump also plays a great role in the diabetic education. Usage of graphs and transparent way of reporting boluses enables children to observe and understand pump's working in the real time. They can control the level of active insulin and its delivery and react to alarms. These reasons lead to increase youngsters' independence and their involvement in the therapy.

Continuous glucose monitoring, when used the majority of time, profits in improving diabetes outcomes and reducing caregivers' worry about hypoglycemia $[12,13]$. The glucometer Contour ${ }^{\circledR}$ Plus Link 2.4 connected with Enlite sensor is a manageable and comfortable system which was confirmed in some clinical trials [14, 15]. Its accuracy and better coherence between blood glucose measured by sensor and glucose meter helped patients to trust the new technology and to significantly reduce the frequency of pricking fingers in order to check glucose level.

Results of the PedsQL survey showed that patients using MiniMed 640G system perceived their quality of life high in all categories considered in the questionnaire. Participants highlighted reduction of problems with measuring blood glucose level because of the accuracy of the sensor, easier exercising and less difficulties in keeping the plan of diabetes control. Patients and their caregivers do not feel as anxious about effectiveness of the treatment and complications of diabetes as before starting to use the $640 \mathrm{G}$ system. Youngsters improved their quality of life by less common headaches, tiredness, sweating and sleeplessness. Insulin pumps generally provide greater flexibility in lifestyle, which may affect different aspects of family burden and children's quality of life $[16,17]$ and these attributes make reference to MiniMed 640G system also.

Clinical study conducted by our team fits in the newest trends of diabetes which use most up-to-date technologies to improve management of the disease and patients' quality of life. Ongoing computer revolution and miniaturization of electronic makes the artificial pancreas be within reach. In the last 3 years, there have been many excellent reviews of progress made in the field of artificial pancreas research [18-21]. Numerous researches confirm that sensor-augmented pump therapy with automated insulin suspension reduces the rate of hypoglycemia in patients with type 1 diabetes $[22,23]$. Innovative MiniMed 640G system completely proves this statement.

Some limitations of the study have to be considered. The number of participants is small due to the recruitment from one particular centre and the fact of launching 640G system in 2015. It may also be triggered by the high cost of this form of therapy and a fact that it is not reimbursed by the national health provider. However, we are going to widen the scope of cooperation to other centers dealing with diabetes and include not only pediatric patients, but also adult ones.

Due to the small size of the research group, most of the comparisons are not powered enough to reach the significance therefore we did not perform statistical analysis to confirm any improvements or deteriorations revealed by surveys.

Short duration of follow-up has to be mentioned, although in this instance necessity of changing habits in self-control and adjusting doses of insulin is a crucial issue. Therefore, even after a short period of time, it enables to evaluate the satisfaction with the new technology which is close to the first pump hybrid system.

We are hoping that expanding our research will enable us to state that we are closer to invent the artificial pancreas than ever before.

\section{Conclusions}

Pediatric patients suffering from diabetes type 1 using 640 system with SmartGuard technology are satisfied with the effects of the therapy and their quality of life measured by PedsQL survey is relatively high.

\section{Acknowledgements}

We would like to thank patients and caregivers for participating in the research.

\section{Conflict of interest}

The authors declare that there is no duality of interest associated with this manuscript.

\section{REFERENCES}

1. Cyganek K, Małecki MT. Zastosowanie ciągłego monitorowania glikemii u chorych na cukrzycę - przegląd dostępnych systemów. Diabetologia Praktyczna. 2010; 11(5): 167-172.

2. New JP, Ajjan R, Pfeiffer AFH, et al. Continuous glucose monitoring in people with diabetes: the randomized controlled Glucose Level Awareness in Diabetes Study (GLADIS). Diabet Med. 2015; 32(5): 609-617, doi: 10.1111/dme.12713, indexed in Pubmed: 25661981.

3. SYSTEM MINIMED Pompa insulinowa MiniMed ${ }^{\circledR} \mathrm{Veo}^{\mathrm{Tm}}$. https:// //www.pompy-medtronic.pl/system-minimed/pompy-insulinoweminimed-veo (November 27, 2016). 
4. SYSTEM MINIMED Pompa insulinowa MiniMed ${ }^{\circledR} 640 \mathrm{G}^{\mathrm{TM}}$. https:// //www.pompy-medtronic.pl/system-minimed/pompy-insulinoweminimed-640g (November 27, 2016).

5. De Bock MI, George CE, et al. Performance of a predictive insulin pump suspension algorithm for prevention of overnight hypoglycaemia. Diabetes. 2014: A240-A241.

6. Choudhary P, Olsen BS, Conget I et al. Performance of the predictive low glucose management feature of the MiniMed 640G system in a user evaluation study. American Diabetes Association 75th Scientific Sessions Boston, USA, 5-9 June 2015.

7. MAPI RESEARCH TRUST. http://mapi-trust.org/ (November 27, 2016).

8. Ly TT, Maahs DM, Rewers A, et al. Assessment and management of hypoglycemia in children and adolescents with diabetes. Pediatric Diabetes. 2014; 15(S20): 180-192, doi: 10.1111/pedi.12174.

9. Driscoll KA, Raymond J, Naranjo D, et al. Fear of Hypoglycemia in Children and Adolescents and Their Parents with Type 1 Diabetes. Curr Diab Rep. 2016; 16(8): 77, doi: 10.1007/s11892-016-0762-2, indexed in Pubmed: 27370530.

10. Tamborlane WV, Swan K, Sikes KA, et al. The renaissance of insulin pump treatment in childhood type 1 diabetes. Rev Endocr Metab Disord. 2006; 7(3): 205-213, doi: 10.1007/s11154-006-9018-9, indexed in Pubmed: 17160722.

11. Haugstvedt A, Wentzel-Larsen T, Graue M, et al. Fear of hypoglycaemia in mothers and fathers of children with Type 1 diabetes is associated with poor glycaemic control and parental emotional distress: a population-based study. Diabet Med. 2010; 27(1): 72-78, doi: 10.1111/j.1464-5491.2009.02867.x, indexed in Pubmed: 20121892.

12. Mauras N, Beck R, Xing D, et al. Diabetes Research in Children Network (DirecNet) Study Group. A randomized clinical trial to assess the efficacy and safety of real-time continuous glucose monitoring in the management of type 1 diabetes in young children aged 4 to $<10$ years. Diabetes Care. 2012; 35(2): 204-210.

13. Bergenstal RM, Tamborlane WV, Ahmann A, et al. Effectiveness of Sensor-Augmented Insulin-Pump Therapy in Type 1 Diabetes. N Eng J Med. 2010; 363(4): 311-320, doi: 10.1056/nejmoa1002853.
14. Keenan DB, Mastrototaro JJ, Zisser H, et al. Accuracy of the Enlite 6-day glucose sensor with guardian and Veo calibration algorithms. Diabetes Technol Ther. 2012; 14(3): 225-231, doi: 10.1089/dia.2011.0199, indexed in Pubmed: 22145851.

15. Evans K, Richardson C, Landry A, et al. Experience With the Enlite Sensor in a Multicenter Pediatric Study. The Diabetes Educator. 2015; 41(1): 31-37, doi: 10.1177/0145721714560589.

16. Streisand R, Swift E, Wickmark T, et al. Pediatric parenting stress among parents of children with type 1 diabetes: the role of selfefficacy, responsibility, and fear. J Pediatr Psychol. 2005; 30(6): 513-521, doi: 10.1093/jpepsy/jsi076, indexed in Pubmed: 16055489.

17. Valenzuela JM, Patino AM, McCullough J, et al. Insulin pump therapy and health-related quality of life in children and adolescents with type 1 diabetes. J Pediatr Psychol. 2006; 31 (6): 650-660, doi: 10.1093/jpepsy/jsj088, indexed in Pubmed: 16322275.

18. Peyser T, Dassau E, Breton M, et al. The artificial pancreas: current status and future prospects in the management of diabetes. Ann N Y Acad Sci. 2014; 1311: 102-123, doi: 10.1111/nyas.12431, indexed in Pubmed: 24725149.

19. Cobelli C, Renard E, Kovatchev B. Artificial pancreas: past, present, future. Diabetes. 2011; 60(11): 2672-2682, doi: 10.2337/ /db11-0654, indexed in Pubmed: 22025773.

20. Kumareswaran K, Evans ML, Hovorka R. Closed-loop insulin delivery: towards improved diabetes care. Discov Med. 2012; 13(69): 159-170, indexed in Pubmed: 22369975.

21. Peyser $T$, Dassau $E$, Breton $M$, et al. The artificial pancreas: current status and future prospects in the management of diabetes. Ann N Y Acad Sci. 2014; 1311: 102-123, doi: 10.1111/nyas.12431, indexed in Pubmed: 24725149.

22. Ly TT, Nicholas JA, Retterath A, et al. Effect of Sensor-Augmented Insulin Pump Therapy and Automated Insulin Suspension vs Standard Insulin Pump Therapy on Hypoglycemia in Patients With Type 1 Diabetes A Randomized Clinical Trial. JAMA. 2013; 310(12): 1240-1247, doi: 10.1001/jama.2013.277818, indexed in Pubmed: 24065010.

23. Zhong A, Choudhary P, McMahon C, et al. Effectiveness of Automated Insulin Management Features of the MiniMed(®) 640G Sensor-Augmented Insulin Pump. Diabetes Technol Ther. 2016; 18(10): 657-663, doi: 10.1089/dia.2016.0216, indexed in Pubmed: 27672710. 